\title{
Hepatitis E: Inzidenz steigt an
}

Die Inzidenz der in tropischen Ländern endemischen Hepatitis $E$ steigt in Deutschland jährlich an. Haben wir ein Problem?

Im Jahr 2006 waren dem Robert KochInstitut genau 51 Hepatitis-E-Fälle gemeldet worden. Seitdem steigt die Anzahl der Meldungen stetig an. Im Jahre 2014 waren es 670 , ein weiteres Jahr später mit 1267 Fällen bereits fast doppelt so viele. Nach Auffassung des RKI ist das vor allem auf eine verstärkte Aufmerksamkeit und Diagnostik zurückzuführen. Bei einer Antikörper-Prävalenz gegen HEV von knapp 17\% in der erwachsenen Bevölkerung deute die Erkrankungshäufigkeit auf einen hohen Anteil asymptomatisch oder subklinisch verlaufender Infektionen hin. Pro Jahr wer- den etwa 70.000 Hepatitis-E-Tote weltweit gezählt.

Hepatitis E ist eine Zoonose. Wichtigste Infektionsquelle in Deutschland ist das Hausschwein. Personen mit häufigem Kontakt zu Schweinen zeigen vergleichsweise hohe Seroprävalenzen. Es sei unklar, welche Fleischprodukte genau die wesentlichen Quellen sind, erklärte Prof. Dr. Heiner Wedemeyer aus Hannover. Die Übertragung über kontaminierte Blutprodukte ist ebenfalls möglich.

Bislang sind fünf Genotypen bekannt, wobei in Mitteleuropa besonders Genotyp 3 verbreitet ist. Die Infektionen verlaufen meist selbstlimitierend und sind mild bis moderat ausgeprägt. Allerdings sind fulminante Verläufe bei bereits bestehenden chronischen Lebererkrankungen, bei immunkomprimierten Patienten sowie bei schwangeren Frauen beobachtet worden.

Das Virus befällt nicht nur die Leber. Es wird überdurchschnittlich häufig bei neurologischen Erkrankungen wie dem Guillain-Barré-Syndrom sowie bei Pankreatitis, Thyreoiditis und hämatologischen Krankheiten gefunden. Künftig müsse es laut Wedemeyer gelingen, Risikopatienten zu identifizieren und antivirale Therapien zu entwickeln. Bislang steht lediglich Ribavirin zur Verfügung. In China ist bereits ein Impfstoff zugelassen. Die Testung von Blutprodukten auf HEV-RNA wird derzeit regional unterschiedlich gehandhabt.

(TM)

Symposium 204 "Clinical Hepatology Practice in 2016: From Science to Therapy" vom 2.-3. September 2016 in Birmingham, Veranstalter: Falk Foundation e.V.

\section{Neue Behandlungsoption in den USA zugelassen}

In den USA ist mit Obeticholsäure kürzlich eine neue Behandlungsoption für Patienten mit primär biliärer Cholangitis (PBC) zugelassen worden.

60-70\% der PBC-Patienten sprechen gut auf Ursodesoxycholsäure (UDCA, z.B. Ursofalk $^{\circledast}$ ) an, das nach wie vor als Mittel der ersten Wahl gilt. Bei etwa einem Drittel der Patienten lässt sich im Langzeitverlauf eine unzureichende Wirkung feststellen, erklärte Prof. Dr. David Jones aus Newcastle-upon-Tyne, England. Er empfahl, ein Jahr nach Therapiebeginn das biochemische Ansprechen mit Bestimmungen der alkalischen Phosphatase (AP), des Bilirubins sowie der Leberenzyme zu überprüfen. Zur Einordnung waren in der Vergangenenheit verschiedene Scores entwickelt worden, etwa die Barcelona-Kriterien, die Paris-I- und Paris-II-Kriterien.

Bei unzureichendem Ansprechen auf UDCA, ausbleibender Wirkung oder UDCA-Unverträglichkeit waren bei etwas weniger als der Hälfte dieser Patienten mit dem FXR-Agonisten Obetichol-

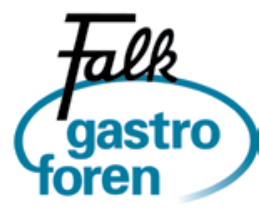

Besuchen Sie das nächste Falk Gastro Forum „Zeitenwende in der
Therapie der CED“ am Samstag, den 12. November 2016 in Kiel;

Besuchen Sie das nächste Falk Gastro Forum „Zeitenwende in de
Therapie der CED“ am Samstag, den 12. November 2016 in Kiel; Infos: www.drfalkpharma.de/veranstaltungen säure (OCA) signifikante Besserungen erzielt worden. In einer kürzlich veröffentlichten Studie bei PBC-Patienten mit unzureichendem Ansprechen auf UDCA war unter 5 bis $10 \mathrm{mg} /$ Tag OCA signifikant häufiger eine Reduktion der AP um mindestens $15 \%$ und ein normaler Bilirubin-Wert erreicht worden als unter Placebo. Die meisten Patienten hatten UDCA weiterhin als Hintergrundmedikation erhalten. Allerdings traten unter OCA, in den USA als Ocaliva ${ }^{\text {Ts }}$ zugelassen, vermehrt unerwünschte Wirkungen wie erhöhter Juckreiz auf [Nevens F et al. NEJM 2016;375:631-643].

Nach Angaben von Jones wird auch für Europa die Zulassung erwartet. 